\title{
Moderate Strontium Loading Induces Rickets in Rats with Mild Chronic Renal Failure
}

\author{
Dagmar-Christiane Fischer ${ }^{\mathrm{a}, \mathrm{d}}$ Claudia Jensen ${ }^{\mathrm{a}}$ Anja Rahn ${ }^{\mathrm{a}}$ Birgit Salewski $^{\mathrm{a}}$ \\ Günther Kundt ${ }^{b}$ Patrick C. D'Haese ${ }^{c}$ Dieter Haffner ${ }^{a}{ }^{d}$ Geert J. Behets ${ }^{c}$

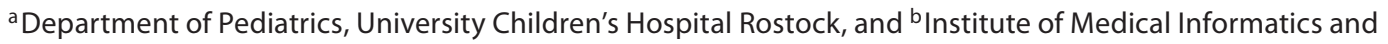 \\ Biometry, University of Rostock, Rostock, Germany; ' Laboratory of Pathophysiology, Department of Medicine, \\ University of Antwerp, Antwerp, Belgium; ${ }^{\text {dDepartment }}$ of Pediatric Kidney, Liver and Metabolic Disease, \\ Hannover Medical School, Hannover, Germany
}

\section{Key Words}

Rickets · Strontium • Post-renal transplant osteoporosis •

Chronic renal failure rats $\cdot$ Growth plate morphology

\begin{abstract}
Background/Aims: Renal osteodystrophy and eventually osteoporosis are serious long-term complications in children with end-stage renal disease before and after renal transplantation. Strontium (Sr) salts are used for treatment of osteoporosis in adults. Methods: To evaluate the time-dependent effects of Sr on growth plate morphology and their reversibility, chronic renal failure (CRF) rats received either normal or Sr-loaded drinking water ( $2 \mathrm{~g} / \mathrm{l} ; \pm 200 \mathrm{mg} / \mathrm{kg} /$ day) for periods of 2, 6 and 12 weeks with or without subsequent washout periods of $0,2,4$ or 8 weeks. Results: While weight gain was not affected by Sr loading, a significant enlargement of the entire growth plate, mainly due to expansion of the hypertrophic zone, was already present after 2 weeks. Sr-loaded animals showed increased osteoid areas and reduced bone formation rates at 2, 6 and 12 weeks compared to controls. This was accompanied by reduced PTH levels and increased serum bone alkaline phosphatase activity. After the washout periods these effects were reversed. In general, the height of the hypertrophic zone was positively correlated with osteoid area and negatively correlated with
\end{abstract}

bone formation rate. Conclusion: Moderate Sr loading in CRF rats results in rapid development of rickets, which is reversible after washout.

Copyright $\odot 2011$ S. Karger AG, Basel

\section{Introduction}

In patients suffering from chronic kidney disease (CKD) the impaired mineral metabolism is strongly associated with both renal osteodystrophy and ectopic vascular calcification and the term chronic kidney disease-mineral bone disorder (CKD-MBD) was coined recently to highlight this association $[1,2]$. In patients with preserved or mildly impaired renal function as well as in the general population an inverse relationship between ectopic calcification and bone mineralization has been noted [3]. Osteoporosis is even in children a rare but serious complication, especially after renal transplantation [4]. Therapeutic measures like bisphosphonates or strontium (Sr)-containing salts are widely used to normalize bone turnover, i.e. to favor bone mineralization and to reduce bone resorption in adults. Moreover, these compounds may have the additional benefit to prevent ectopic calcifications [5].

Sr has been shown to exert dose-dependent positive or negative effects on bone metabolism and mineralization 
[6]. Sr is a natural constituent of food and beverages, with concentrations ranging from 0.3 to $5.1 \mathrm{mg} / \mathrm{kg}$ in meat and vegetables up to $25 \mathrm{mg} / \mathrm{kg}$ in cereals, grains and seafood $[6,7]$. Calcium and Sr are highly comparable with respect to their chemical properties and show quite similar biological behavior, except that $\mathrm{Sr}$ levels are not homeostatically controlled. Gastrointestinal absorption is the main route of entry and almost all of the Sr absorbed accumulates in the skeleton. While under physiological conditions, the Sr/calcium ratios in bone and serum are comparable and vary between 1:1,000 and 1:2,000, skeletal accumulation of Sr might become relevant under conditions of low dietary calcium intake and/or exposure to a Sr-enriched diet [6-8]. Furthermore, in chicken with normal renal function a high dietary intake of Sr was shown to interfere with renal 1,25-dihydroxycholecalciferol synthesis. The thereby further diminished calcium absorption finally led to rickets $[9,10]$.

In experimental uremia, high dosages of $\mathrm{Sr}$ induce mineralization defects and osteomalacia $[11,12]$. Likewise, osteomalacia in CKD patients on hemodialysis has been strongly associated with the $\mathrm{Sr}$ concentration in dialysis fluids and probably additional effects related to Sr-contaminated phosphate binders $[7,13]$. On the contrary, clinical and experimental studies have shown that low dosages of $\mathrm{Sr}$ are able to uncouple bone turnover, i.e. to reduce bone resorption and to increase bone formation secondary to stimulation of osteoblastic activity $[14,15]$. Thus, the therapeutic window for Sr appears to be rather narrow. Beyond exogenous supplementation, a declining renal function is likely to contribute to skeletal $\mathrm{Sr}$ accumulation and may have the potential to convert a beneficial dosage into a deleterious one. This might even be of importance in children requiring treatment for glucocorticoid-induced osteoporosis after renal transplantation, especially in areas with high environmental Sr exposure [16].

Recently, we have shown that rather moderate Sr loading induces osteomalacia in rats with mild chronic renal failure (CRF) [17]. However, the effects of Sr on the growth plate in this model have not been addressed so far. Therefore, we investigated the time-dependent effects of Sr on growth plate morphology and its reversibility in this setting.

\section{Materials and Methods}

\section{Animals and Experimental Protocol}

All animal handling and experiments outlined in this study were in accordance with the accepted principles of welfare of animals used in science and were approved by the local committee for animal experiments of the Antwerp University. This is a continuation of our previous study on the evolution and reversibility of Sr-induced osteomalacia in CRF rats [17]. Histological slides derived from the same specimens used for bone histomorphometry were used to assess growth plate morphology. In brief, male Wistar rats $(n=79)$ weighing approximately $150 \mathrm{~g}$ underwent $5 / 6$ nephrectomy for induction of CRF. Two weeks later, animals were randomized to receive either pure tap water or tap water supplemented with $\mathrm{Sr}(2 \mathrm{~g} / \mathrm{l}$; equivalent to a daily intake of approx. 200 $\mathrm{mg} / \mathrm{kg}$ b.w.) for 2,6 and 12 weeks with and without subsequent washout periods of $0,2,4$ or 8 weeks. All animals had free access to standard rat chow $(0.8 \% \mathrm{Ca}, 0.67 \% \mathrm{P})$ and water throughout the experiment. Intraperitoneal injections of tetracycline $(30 \mathrm{mg} / \mathrm{kg}$ b.w.) and demeclocycline ( $25 \mathrm{mg} / \mathrm{kg}$ b.w.) were performed 7 and 3 days prior to sacrifice to allow measurement of dynamic bone parameters. Per rat, one tibia was removed, freed from soft tissue and further processed for embedding in methylmethacrylate essentially as described [17].

\section{Methods: Analysis of Growth Plate Architecture and}

Histomorphometric Assessment of Bone

Longitudinal sections (approx. $5 \mu \mathrm{m}$ ) were cut from the same specimen used for bone histomorphometry. Sections stained according to Goldner were used to assess growth plate morphology. Slides were viewed at a magnification of $100 \times$ and images of the entire growth plate were taken to determine heights of the hypertrophic and proliferative zones, respectively. Established morphological criteria were applied to discriminate between hypertrophic and proliferative zones [18, 19]. At least 30 measurements per sample were taken. As the resting zone was almost absent in the vast majority of animals, the sum of the heights from hypertrophic and proliferative zone was taken as the total height of the growth plate. Additional sections were etched with $1 \%$ formic acid (30 s) and stained with toluidine blue $\left(0.7 \%\right.$ in $0.1 \mathrm{M} \mathrm{NaH}_{2} \mathrm{PO}_{4} /$ $\left.\mathrm{Na}_{2} \mathrm{HPO}_{4} \mathrm{pH} 7.2\right)$ as described recently $[20,21]$.

\section{Blood and Urine Chemistry}

Established methods from routine clinical chemistry were used for quantification of serum creatinine, calcium and phosphate as well as for determination of proteinuria, urinary creatinine and urinary phosphorous [17]. Bone alkaline phosphatase was analyzed by an optimized agarose gel electrophoretic assay [17]. PTH serum levels were measured by an immunoradiometric assay specific for rat intact PTH (Immutopics, San Clemente, Calif., USA). A Zeeman 3030 atomic absorption spectrometer was used to measure calcium and $\mathrm{Sr}$ concentrations in serum, urine and bone.

\section{Statistical Analysis}

Data were analyzed using the SPSS statistical package 15.0 (SPSS Inc., Chicago, Ill., USA). Descriptive statistics including mean and SD for continuous variables were computed. The Kolmogorov-Smirnov test was applied to assess normal distribution. Differences were investigated using the Mann-Whitney rank test. Data are expressed as mean \pm SEM. All $p$ values resulted from two-sided statistical tests and $\mathrm{p}<0.05$ was considered to be significant. 
Table 1. Weight gain per week (w), height of the proliferative and hypertrophic zones of the growth plate, bone formation rates and relative osteoid area in Sr-loaded and control CRF rats

\begin{tabular}{|c|c|c|c|c|c|c|}
\hline Mode of treatment & $\begin{array}{l}\text { Weight gain } \\
\text { g/week }\end{array}$ & $\begin{array}{l}\text { Total growth } \\
\text { plate height, } \mu \mathrm{m}\end{array}$ & $\begin{array}{l}\text { Proliferative } \\
\text { zone height, } \mu \mathrm{m}\end{array}$ & $\begin{array}{l}\text { Hypertrophic } \\
\text { zone height, } \mu \mathrm{m}\end{array}$ & $\begin{array}{l}\text { Bone formation } \\
\text { rate, } \mu \mathrm{m}^{2} / \mathrm{mm}^{2} / \text { day }\end{array}$ & $\begin{array}{l}\text { Osteoid area per } \\
\text { total bone, } \%\end{array}$ \\
\hline $2 \mathrm{w}$ control $(\mathrm{n}=5)$ & $4.40 \pm 2.58$ & $186.3 \pm 1.86$ & $127.3 \pm 1.3^{\mathrm{a}, \mathrm{d}}$ & $59.0 \pm 2.8$ & $1,694 \pm 1,013$ & $6.5 \pm 1.7^{\mathrm{a}}$ \\
\hline $2 \mathrm{w} S r(n=5)$ & $4.70 \pm 2.34$ & $253.2 \pm 24.3$ & $138.5 \pm 4.0^{\mathrm{a}}$ & $114.7 \pm 21.7$ & $170 \pm 152.1$ & $18.1 \pm 4.3^{\mathrm{a}}$ \\
\hline $2 \mathrm{w} S r+2 \mathrm{w}$ washout $(\mathrm{n}=5)$ & $7.40 \pm 2.30$ & $184.3 \pm 6.17$ & $121.0 \pm 4.7$ & $63.3 \pm 2.3$ & $460 \pm 459.7$ & $5.6 \pm 2.5$ \\
\hline $2 \mathrm{w} S r+8 w$ washout $(n=6)$ & $4.46 \pm 0.89$ & $159.6 \pm 7.27$ & $100.2 \pm 4.2^{\mathrm{d}}$ & $59.4 \pm 3.7$ & $525 \pm 260.1$ & $8.4 \pm 2.6$ \\
\hline $6 \mathrm{w}$ control $(n=5)$ & $9.07 \pm 1.98$ & $159.9 \pm 3.46$ & $110.8 \pm 2.3^{\mathrm{b}, \mathrm{f}}$ & $49.2 \pm 2.64^{\mathrm{b}, \mathrm{e}, \mathrm{f}}$ & $833 \pm 370.7$ & $3.4 \pm 1.3^{\mathrm{d}}$ \\
\hline $6 \mathrm{w} \operatorname{Sr}(\mathrm{n}=5)$ & $5.92 \pm 1.28$ & $368.5 \pm 64.8$ & $166.5 \pm 4.9^{\mathrm{b}}$ & $201.9 \pm 60.8^{b}$ & $0 \pm 0$ & $38.2 \pm 7.1^{\mathrm{d}, \mathrm{g}}$ \\
\hline $6 \mathrm{w} S \mathrm{Sr}+2 \mathrm{w}$ washout $(\mathrm{n}=6)$ & $2.35 \pm 2.04$ & $167.4 \pm 15.8$ & $101.9 \pm 8.6$ & $65.5 \pm 7.4^{\mathrm{e}}$ & $0 \pm 0$ & $32.0 \pm 8.1$ \\
\hline $6 \mathrm{w} S R+8 w$ washout $(n=7)$ & $5.52 \pm 1.72$ & $150.0 \pm 2.89$ & $92.0 \pm 2.4^{\mathrm{f}}$ & $58.0 \pm 1.3^{\mathrm{f}}$ & $172 \pm 137.6$ & $5.2 \pm 1.0^{\mathrm{g}}$ \\
\hline $12 \mathrm{w}$ control $(\mathrm{n}=5)$ & $2.10 \pm 2.61$ & $152.5 \pm 3.58$ & $101.6 \pm 3.4^{\mathrm{g}}$ & $50.9 \pm 3.2^{c}$ & $1,054 \pm 551.4^{\mathrm{h}}$ & $6.8 \pm 2.5^{\mathrm{h}}$ \\
\hline $12 \mathrm{w} \operatorname{Sr}(\mathrm{n}=5)$ & $3.20 \pm 1.97$ & $201.7 \pm 27.0$ & $111.7 \pm 11.6$ & $89.9 \pm 16.9^{c, h}$ & $0 \pm 0^{\mathrm{h}, \mathrm{j}, \mathrm{k}}$ & $31.5 \pm 8.3^{\mathrm{h}, \mathrm{j}, \mathrm{k}}$ \\
\hline $12 \mathrm{w} S \mathrm{Sr}+2 \mathrm{w}$ washout $(\mathrm{n}=4)$ & $7.00 \pm 0.61$ & $145.2 \pm 4.56$ & $93.4 \pm 3.8$ & $51.8 \pm 1.3^{\mathrm{h}}$ & $941 \pm 208.5^{j}$ & $8.1 \pm 4.5^{j}$ \\
\hline $12 \mathrm{w}$ Sr $+4 \mathrm{w}$ washout $(\mathrm{n}=9)$ & $5.64 \pm 1.19$ & $129.0 \pm 4.97$ & $83.1 \pm 3.6^{\mathrm{g}}$ & $45.9 \pm 1.8$ & $667 \pm 201.7^{\mathrm{k}}$ & $9.2 \pm 4.1^{\mathrm{k}}$ \\
\hline
\end{tabular}

Values are given as mean \pm SEM.

Identical superscripts denote significant differences $(\mathrm{p}<0.05)$ between groups sharing the same superscript.

Table 2. Serum biochemistry in CRF rats receiving normal or Sr-supplemented drinking water (2 g/l) for 2, 6 or 12 weeks (w) with and without subsequent washout periods

\begin{tabular}{|c|c|c|c|c|c|}
\hline Mode of treatment & $\begin{array}{l}\text { Creatinine } \\
\mu \mathrm{mol} / 1\end{array}$ & $\begin{array}{l}\text { Calcium } \\
\mathrm{mmol} / \mathrm{l}\end{array}$ & $\begin{array}{l}\text { Phosphate } \\
\mathrm{mmol} / \mathrm{l}\end{array}$ & $\begin{array}{l}\text { Bone-ALP } \\
\text { activity, U/1 }\end{array}$ & $\begin{array}{l}\text { PTH } \\
\mathrm{pg} / \mathrm{ml}\end{array}$ \\
\hline $2 \mathrm{w}$ control $(\mathrm{n}=5)$ & $111.4 \pm 17.8$ & $2.51 \pm 0.01$ & $2.02 \pm 0.14$ & $32.6 \pm 5.3^{\mathrm{a}}$ & $110.5 \pm 39.5^{\mathrm{a}}$ \\
\hline $2 \mathrm{w} \operatorname{Sr}(\mathrm{n}=5)$ & $99.0 \pm 12.9$ & $2.47 \pm 0.01$ & $1.85 \pm 0.22$ & $63.6 \pm 3.5^{\mathrm{a}, \mathrm{b}, \mathrm{c}}$ & $18.2 \pm 5.0^{\mathrm{a}, \mathrm{b}, \mathrm{c}}$ \\
\hline $2 \mathrm{w} S r+2 \mathrm{w}$ washout $(\mathrm{n}=5)$ & $84.0 \pm 13.9$ & $2.43 \pm 0.03$ & $1.92 \pm 0.13$ & $37.3 \pm 3.0^{\mathrm{b}}$ & $71.3 \pm 11.6^{\mathrm{b}}$ \\
\hline $2 \mathrm{w} S r+8 w$ washout $(n=6)$ & $162.7 \pm 31.7$ & $2.40 \pm 0.06$ & $2.02 \pm 0.28$ & $33.0 \pm 5.8^{\mathrm{c}}$ & $205.0 \pm 9.8^{c}$ \\
\hline $6 \mathrm{w}$ control $(\mathrm{n}=5)$ & $83.1 \pm 14.9$ & $2.49 \pm 0.05$ & $2.25 \pm 0.23$ & $19.8 \pm 3.7^{\mathrm{d}, \mathrm{e}, \mathrm{f}}$ & $59.8 \pm 8.0$ \\
\hline $6 \mathrm{w} \operatorname{Sr}(\mathrm{n}=5)$ & $108.3 \pm 3.8$ & $2.44 \pm 0.02$ & $2.03 \pm 0.17$ & $69.0 \pm 6.0^{\mathrm{d}, \mathrm{g}}$ & $7.7 \pm 1.6$ \\
\hline $6 w S r+2 w$ washout $(n=6)$ & $160.9 \pm 28.7$ & $2.40 \pm 0.04$ & $1.60 \pm 0.13$ & $58.4 \pm 5.9^{\mathrm{e}}$ & $197.4 \pm 65.1$ \\
\hline $6 \mathrm{w} S R+8 w$ washout $(n=7)$ & $119.3 \pm 5.5$ & $2.49 \pm 0.05$ & $2.26 \pm 0.18$ & $37.0 \pm 1.6^{\mathrm{f}, \mathrm{g}}$ & $70.5 \pm 2.4$ \\
\hline $12 \mathrm{w}$ control $(\mathrm{n}=5)$ & $127.3 \pm 28.3$ & $2.52 \pm 0.02$ & $2.19 \pm 0.28$ & $29.2 \pm 2.5^{\mathrm{h}, \mathrm{i}}$ & $159.6 \pm 62.6$ \\
\hline $12 \mathrm{w} \operatorname{Sr}(\mathrm{n}=5)$ & $111.4 \pm 9.1$ & $2.51 \pm 0.08$ & $1.45 \pm 0.29$ & $62.6 \pm 1.2^{\mathrm{h}, \mathrm{k}}$ & $38.4 \pm 11.5$ \\
\hline $12 \mathrm{w} S \mathrm{r}+2 \mathrm{w}$ washout $(\mathrm{n}=4)$ & $92.8 \pm 4.4$ & $2.54 \pm 0.06$ & $2.66 \pm 0.68$ & $48.0 \pm 7.0^{\mathrm{i}}$ & $49.0 \pm 22.3$ \\
\hline $12 \mathrm{w} S \mathrm{SR}+4 \mathrm{w}$ washout $(\mathrm{n}=9)$ & $99.5 \pm 8.9$ & $2.49 \pm 0.01$ & $2.07 \pm 0.13$ & $39.7 \pm 4.8^{\mathrm{k}}$ & $229.0 \pm 65.5$ \\
\hline
\end{tabular}

Results are given as mean \pm SEM.

Identical superscripts denote significant differences $(\mathrm{p}<0.05)$ between groups sharing the same superscript.

\section{Results}

During the study, daily food intake (approx. $20 \mathrm{~g} /$ day) and body weight gain did not differ between CRF controls and Sr-loaded animals (table 1). Sr loading did not affect serum creatinine, calcium, and phosphorus levels (table 2). Bone alkaline phosphatase activity was significantly increased at 2, 6 and 12 weeks of Sr loading, which was reversed after washout (table 2). Serum PTH levels were significantly decreased after 2 weeks of Sr loading and returned to normal after washout. Similar trends were noted after 6 and 12 weeks of Sr loading. Serum and urine concentrations of $\mathrm{Sr}$ were markedly elevated after Sr loading (approx. $30 \mu \mathrm{g} / \mathrm{ml}$ and $1.8 \mathrm{mg} / 24 \mathrm{~h}$ ) but dropped rapidly after withdrawal. However, Sr continuously accumulated in bone and only a limited decrease 


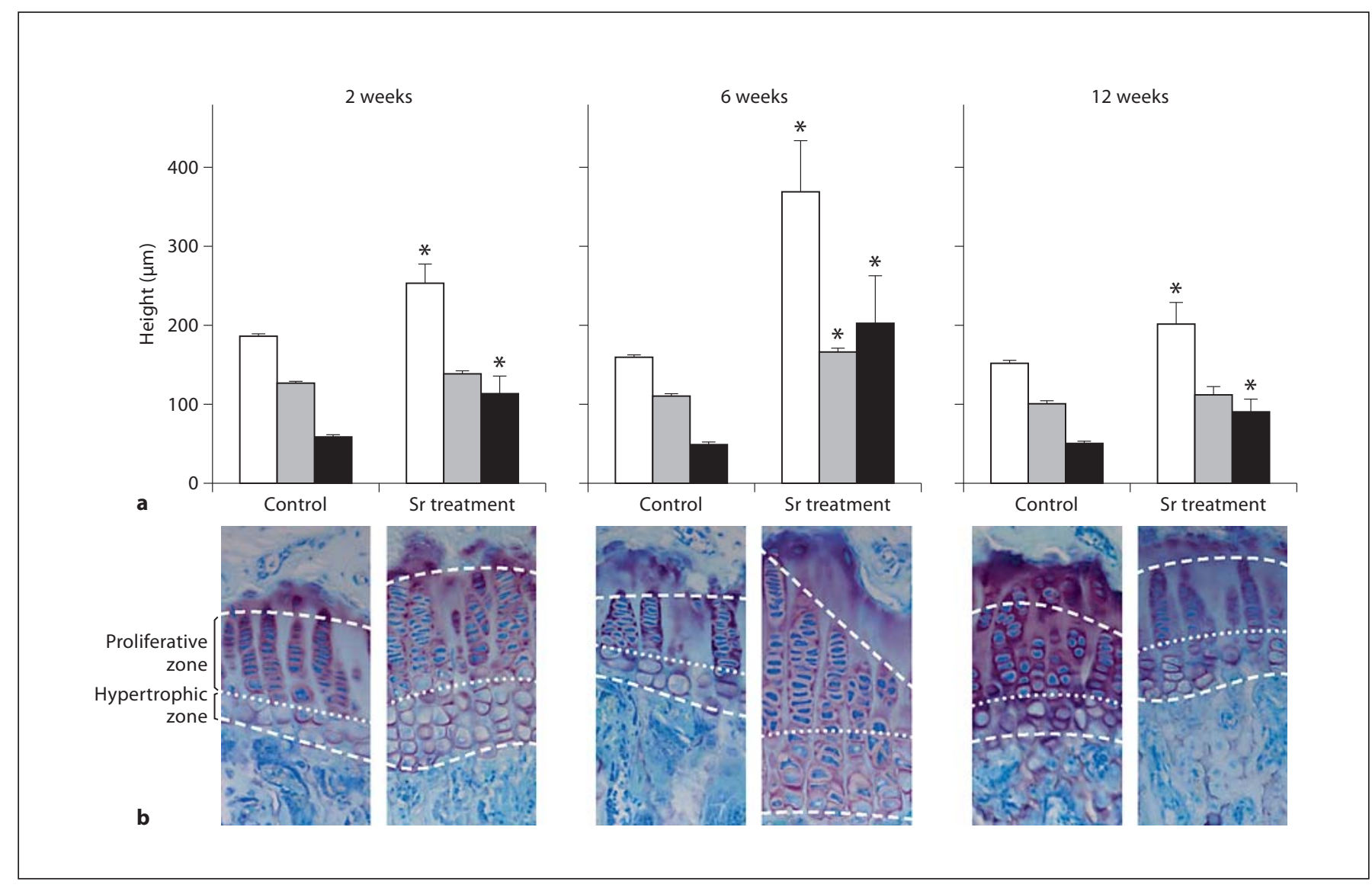

Fig. 1. Morphometric evaluation of the growth plate. a Total height of the growth plate ( $\square$ ) as well as heights of the proliferative (眷) and hypertrophic zone ( $\square$ ). Values are given as mean \pm SEM. b Representative sections derived from untreated and Sr-loaded CRF rats. $\times 100$.

after withdrawal with an estimated half-life for removal of Sr of $9.7 \pm 2.9$ weeks was observed (data not shown).

In untreated CRF rats, growth plate height decreased with increasing age. By contrast, in Sr-loaded animals a significant enlargement of the entire growth plate, mainly due to expansion of the hypertrophic zone, was noted. This effect was already present after 2 weeks of treatment, reached its maximum after 6 weeks and was reversed after washout (fig. 1; table 1). Osteoid areas were significantly increased at 6 and 12 weeks of Sr treatment, and were normalized within 8 weeks of washout (table 1). Bone formation rate tended to be reduced after 2 and 6 weeks of Sr administration. After 12 weeks of treatment, a significantly reduced bone formation rate was seen. At the end of the washout periods, bone formation rates recovered, but did not reach control values. Regardless of duration or mode of treatment, the height of the hypertrophic zone was positively correlated with the relative osteoid area $(\mathrm{r}=0.527, \mathrm{p}<0.001)$ and negatively correlated with the bone formation rate $(\mathrm{r}=-0.443, \mathrm{p}<0.001$; fig. 2).

\section{Discussion}

In children suffering from end-stage renal disease the development of renal osteodystrophy, growth retardation, and rickets as well as ectopic arterial calcifications are serious features of CKD-MBD. Even after renal transplantation the situation may not fully revert to normal and glucocorticoid-induced osteoporosis might occur [16]. According to current knowledge, some types of renal osteodystrophy reflect a disturbed continuous efflux of mineral from bone and the inability of the bone to mineralize properly [1]. Apart from rickets, this situation closely resembles osteoporosis and thus anti-osteoporot- 

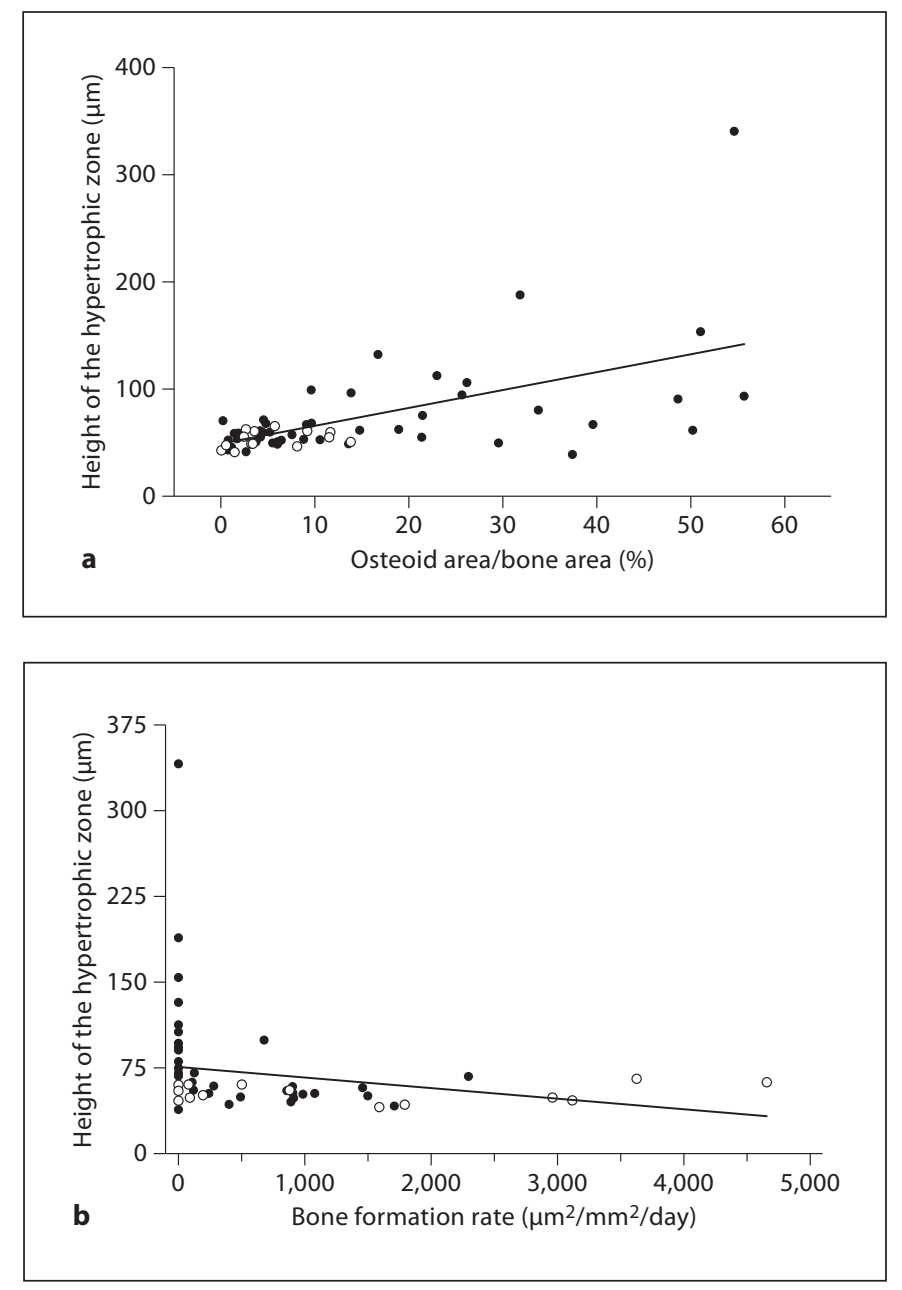

Fig. 2. Height of the hypertrophic zone of the tibial growth plate as a function of relative osteoid area (a) and bone formation rate (b). The height of the hypertrophic zone was positively correlated with the relative osteoid area $(\mathrm{r}=0.527, \mathrm{p}<0.001)$ and negatively correlated with the bone formation rate $(\mathrm{r}=-0.443, \mathrm{p}<0.001)$ Sr-loaded animals $(\bullet)$ and CRF controls $(\bigcirc)$ are indicated.

ic drugs, i.e. those directed to enforce bone formation and mineral binding in bone as well as to reduce efflux from bone, gained special interest for treatment of renal osteodystrophy. Beyond this, such an approach is at least in theory expected to reduce the risk of ectopic calcifications [5].

Currently, bisphosphonates, either N-containing or not, and the Sr salt of ranelic acid are used to treat osteoporosis. The utilization of $\mathrm{Sr}$ for this purpose is of special interest, as $\mathrm{Sr}$ is a natural constituent of food and beverages. Calcium and Sr belong to the alkaline earth series and both cations possess quite similar chemical proper- ties (ionic radius, charge-to-size ratio, coordination number), which translate into rather comparable interactions with organic and inorganic components [22]. While their major metabolic pathways related to gastrointestinal uptake and excretion probably utilize similar if not at all identical processes, at the cellular level discrimination between both cations occurs [22]. Intestinal and renal calcium-specific channels as well as a variety of intracellular Ca-binding proteins showed significantly lower affinity for Sr binding [22-24]. Beyond this, in the presence of normal Sr levels, the extracellular concentration of calcium exceeds $\mathrm{Sr}$ by several orders of magnitude, thereby lowering the probability for Sr uptake [22]. While under physiological conditions these mechanisms are sufficient to prevent Sr-related deleterious effects, they likely become exhausted under conditions of continuous Sr loading in combination with impaired renal excretion. Under such circumstances, Sr interferes not only with calciumdependent cellular processes (see below) but also with the formation and subsequent biophysical/biochemical properties of hydroxyapatite. Although $\mathrm{Sr}$ is grossly excluded from properly crystallized apatite, at high concentrations it may replace calcium secondary to heteroionic exchange [6]. This replacement will result in a slight deformation of the crystal lattice, which in turn will ease subsequent $\mathrm{Sr}$ incorporation $[22,25,26]$. In the long run, this may decrease skeletal calcium content. Besides being incorporated into hydroxyapatite, $\mathrm{Sr}$ can be adsorbed at the crystal surface and was shown to inhibit subsequent crystal growth $[11,12,26,27]$. Beyond these effects on apatite formation, Sr was shown to interfere with osteoblast differentiation in vitro already at low extracellular concentrations [28].

In the present study, we have shown that moderate $\mathrm{Sr}$ loading did not affect weight gain in rats with mild renal failure. However, 2 weeks of Sr loading were sufficient to induce rickets, i.e. expansion of the hypertrophic zone and increased alkaline phosphatase activity. The effect was at maximum after 6 weeks of treatment and turned out to be completely reversible during washout. The enlargement of the growth plate was mainly due to expansion of the hypertrophic zone, indicating that the fade of chondrocytes from proliferative to hypertrophic state is not or only mildly affected. Instead, mineralization of the extracellular matrix either provided by osteoblasts or hypertrophic chondrocytes is significantly disturbed. Although not formally proven in the present study, a reduced rate of matrix vesicle degradation might have contributed to the observed mineralization defect $[29,30]$. This mineralization defect in turn delays the apoptosis of 
the hypertrophic chondrocytes, leading to widening of the hypertrophic zone. The link between defective mineralization and widening of the growth plate has already been shown in hypophosphatasia and in animals with growth impairment secondary to CRF $[31,32]$. While interference of Sr with the formation of apatite is likely to be a major contributor to impaired bone mineralization, interference with cellular processes might be even more relevant in matrix mineralization mediated by hypertrophic chondrocytes. Cellular uptake of $\mathrm{Sr}$ can occur via calcium channels and once internalized, the intracellular concentrations of $\mathrm{Sr}$ and calcium might be quite comparable [22]. Furthermore, Sr may bind to intracellular calcium-binding proteins, thereby affecting calcium-regulated processes as well $[33,34]$.

In this regard, the recent observation that $\mathrm{Sr}$ can act as an agonist of the calcium-sensing receptor (CaSR) deserves special interest [15]. In addition, the existence of a novel, osteoblast-specific G-protein-coupled cation-sensing receptor with high specificity for $\mathrm{Sr}$ has been described [35]. In the present study, Sr loading in CRF rats was associated with decreased PTH levels, which might also have contributed to low bone formation rates. This is of special relevance with respect to the use of Sr in CKD patients before or after renal transplantation. These patients are already at risk for low turnover bone disease and instead of improvement this may progress into adynamic bone disease, the more since it is well known that Sr may exert a calcimimetic action at the level of the CaSR [36]. Low PTH levels may be at least partly due to activation of the CaSR in the parathyroid gland [37]. In addition, epiphyseal chondrocytes also express the CaSR and its activation affects cell proliferation and differentiation in vitro [38]. Thus, Sr-induced rickets may also be a consequence of its interference with the CaSR in epiphyseal chondrocytes. Recently, it was shown that the calcimimetic agent cinacalcet does not impact epiphyseal chondrocyte function and longitudinal growth in healthy and uremic rats, but rather exerts anabolic effects [39]. Also not formally proven, this observation makes it rather unlikely that Sr induced activation of the CaSR in epiphyseal chondrocytes contributed to the development of rickets in the present study.

Terminally differentiated, mineralization-competent chondrocytes release matrix vesicles, which are required to initiate matrix mineralization. These matrix vesicles contain annexin II, V, and VI channels, which mediate the influx of calcium as the initial step for formation of a mineral phase inside the vesicles. In vitro experiments have shown that blocking of these annexin channels with specific antibodies led to inhibition of matrix mineralization [40]. Given that cellular uptake of Sr can occur via calcium channels, Sr binding to annexins might occur as well. This would be in line with the known competition between $\mathrm{Sr}$ and calcium for binding to the mineralizable extracellular matrix.

This study was initially designed to investigate the effects of therapeutic dosages of Sr on bone mineralization under the conditions of mild CRF. Thus, caution has to be taken when extrapolating of our data on the growth plate morphology to the interference of Sr with longitudinal growth. In particular, data on longitudinal growth, chondrocyte proliferation rates and $\mathrm{Sr}$ accumulation within the growth plates were not recorded within the frame of the current study. However, in healthy animals, high-dose Sr loading (1.5\% Sr in diet, i.e. approx. $375 \mathrm{mg} /$ day), was shown to induce rickets, and to diminish both tibial growth and body weight gain to a similar extent [29]. By contrast, in the present study, moderate Sr loading $(200 \mathrm{mg} / \mathrm{kg} /$ day equivalent to $30-100 \mathrm{mg} /$ day $)$ did not affect weight gain, making a significant impairment of longitudinal growth rather unlikely.

In conclusion, moderate $\mathrm{Sr}$ loading in rats with mild renal failure resulted in rapid development of rickets, which was reversible after washout. The Sr-induced effects on bone mineralization and growth plate morphology are most likely due to both interference with calciumregulated processes at the cellular level and physicochemical interference with formation of hydroxyapatite crystals. The therapeutic window for $\mathrm{Sr}$ is apparently small and directly related to renal function, thereby limiting its use as an anti-osteoporotic agent in children after renal transplantation.

\section{Acknowledgements}

The study was funded by a grant (FORUN Program) from the Medical Faculty, University of Rostock. This paper was presented orally at the 43rd Annual Scientific Meeting of the European Society for Pediatric Nephrology, Birmingham, UK, 2009.

\section{Disclosure Statement}

The authors have no conflicts of interest to disclose. 


\section{References}

-1 Moe S, Drueke T, Cunningham J, Goodman W, Martin K, Olgaard K, Ott S, Sprague S, Lameire N, Eknoyan G: Definition, evaluation, and classification of renal osteodystrophy: a position statement from Kidney Disease: Improving Global Outcomes (KDIGO). Kidney Int 2006;69:1945-1953.

-2 Moe SM, Drueke T, Lameire N, Eknoyan G: Chronic kidney disease-mineral-bone disorder: a new paradigm. Adv Chronic Kidney Dis 2007; 14:3-12.

$\checkmark 3$ Hofbauer LC, Brueck CC, Shanahan CM, Schoppet M, Dobnig H: Vascular calcification and osteoporosis - from clinical observation towards molecular understanding. Osteoporos Int 2007;18:251-259.

$\checkmark 4$ El-Husseini AA, El-Agroudy AE, El-Sayed MF, Sobh MA, Ghoneim MA: Treatment of osteopenia and osteoporosis in renal transplant children and adolescents. Pediatr Transplant 2004;8:357-361.

$\checkmark 5$ Persy V, De Broe M, Ketteler M: Bisphosphonates prevent experimental vascular calcification: treat the bone to cure the vessels? Kidney Int 2006;70:1537-1538.

6 Cabrera WE, Schrooten I, De Broe ME, D'Haese PC: Strontium and bone. J Bone Miner Res 1999;14:661-668.

7 Cohen-Solal M: Strontium overload and toxicity: impact on renal osteodystrophy. Nephrol Dial Transplant 2002;17(suppl 2): 30-34.

8 Özgür S, Sumer H, Kocoglu G: Rickets and soil strontium. Arch Dis Child 1996;75:524526.

-9 Omdahl JL, DeLuca HF: Strontium-induced rickets: metabolic basis. Science 1971;174: 949-951.

$>10$ Omdahl JL, DeLuca HF: Rachitogenic activity of dietary strontium. I. Inhibition of intestinal calcium absorption and 1,25-dihydroxycholecalciferol synthesis. J Biol Chem 1972;247:5520-5526.

- 11 Schrooten I, Cabrera W, Goodman WG, Dauwe S, Lamberts LV, Marynissen R, Dorrine W, De Broe ME, D'Haese PC: Strontium causes osteomalacia in chronic renal failure rats. Kidney Int 1998;54:448-456.

-12 Schrooten I, Behets GJ, Cabrera WE, Vercauteren SR, Lamberts LV, Verberckmoes SC, Bervoets AJ, Dams G, Goodman WG, De Broe ME, D'Haese PC: Dose-dependent effects of strontium on bone of chronic renal failure rats. Kidney Int 2003;63:927-935.

-13 Schrooten I, Elseviers MM, Lamberts LV, De Broe ME, D'Haese PC: Increased serum strontium levels in dialysis patients: an epidemiological survey. Kidney Int 1999;56: 1886-1892.

- 14 Grynpas MD, Hamilton E, Cheung R, Tsouderos Y, Deloffre P, Hott M, Marie PJ: Strontium increases vertebral bone volume in rats at a low dose that does not induce detectable mineralization defect. Bone 1996; 18:253-259.
15 Hamdy NA: Strontium ranelate improves bone microarchitecture in osteoporosis Rheumatology (Oxford) 2009;48(suppl 4): iv9-13.

16 Wesseling K, Bakkaloglu S, Salusky I: Chronic kidney disease mineral and bone disorder in children. Pediatr Nephrol 2008; 23:195-207.

17 Oste L, Bervoets AR, Behets GJ, Dams G, Marijnissen RL, Geryl H, Lamberts LV, Verberckmoes SC, Van Hoof VO, De Broe ME, D'Haese PC: Time evolution and reversibility of strontium-induced osteomalacia in chronic renal failure rats. Kidney Int 2005 . 67:920-930.

18 Cobo A, Lopez JM, Carbajo E, Santos F, Alvarez J, Fernandez M, Weruaga A: Growth plate cartilage formation and resorption are differentially depressed in growth-retarded uremic rats. J Am Soc Nephrol 1999;10:971979.

19 Cruz-Orive LM, Hunziker EB: Stereology for anisotropic cells: application to growth cartilage. J Microsc 1986;143:47-80.

20 Eurell JA, Sterchi DL: Microwaveable toluidine blue stain for surface staining of undecalcified bone sections. J Histotechnol 1994; 17:357-359.

-21 Fischer DC, Jensen C, Rahn A, Kundt G, Behets GJ, Haffner D: Ibandronate affects bone growth and mineralization in rats with normal and reduced renal function. Pediatr Nephrol 2011;26:111-117.

22 Staub JF, Foos E, Courtin B, Jochemsen R, Perault-Staub AM: A nonlinear compartmental model of Sr metabolism. II. Its physiological relevance for Ca metabolism. Am J Physiol Regul Integr Comp Physiol 2003. 284:R835-R852.

23 Peng JB, Chen XZ, Berger UV, Vassilev PM, Tsukaguchi H, Brown EM, Hediger MA: Molecular cloning and characterization of a channel-like transporter mediating intestinal calcium absorption. J Biol Chem 1999; 274:22739-22746.

24 Vennekens R, Hoenderop JG, Prenen J, Stuiver M, Willems PH, Droogmans G, Nilius B, Bindels RJ: Permeation and gating properties of the novel epithelial $\mathrm{Ca}^{2+}$ channel. J Biol Chem 2000;275:3963-3969.

25 Christoffersen J, Christoffersen MR, Kolthoff N, Barenholdt O: Effects of strontium ions on growth and dissolution of hydroxyapatite and on bone mineral detection. Bone 1997;20:47-54.

26 Verberckmoes SC, Behets GJ, Oste L, Bervoets AR, Lamberts LV, Drakopoulos M, Somogyi A, Cool P, Dorrine W, De Broe ME, D'Haese PC: Effects of strontium on the physicochemical characteristics of hydroxyapatite. Calcif Tissue Int 2004;75:405-415.
27 Boivin G, Deloffre P, Perrat B, Panczer G, Boudeulle M, Mauras Y, Allain P, Tsouderos Y, Meunier PJ: Strontium distribution and interactions with bone mineral in monkey iliac bone after strontium salt (S 12911) administration. J Bone Miner Res 1996;11: 1302-1311

28 Verberckmoes SC, De Broe ME, D’Haese PC: Dose-dependent effects of strontium on osteoblast function and mineralization. Kidney Int 2003;64:534-543.

29 Matsumoto A: Effect of strontium on the epiphyseal cartilage plate of rat tibiae - histological and radiographic studies. Jpn J Pharmacol 1976;26:675-681.

30 Reinholt FP, Hjerpe A, Jansson K, Engfeldt B: Stereological studies on the epiphyseal growth plate in strontium-induced rickets. With special reference to the distribution of matrix vesicles. J Bone Joint Surg Am 1984; 66:1274-1280.

31 Alvarez J, Balbin M, Fernandez M, Lopez JM: Collagen metabolism is markedly altered in the hypertrophic cartilage of growth plates from rats with growth impairment secondary to chronic renal failure. J Bone Miner Res 2001;16:511-524.

32 Anderson HC: Molecular biology of matrix vesicles. Clin Orthop Relat Res 1995;314: 266-280

33 Mermier P, Hasselbach W: Comparison between strontium and calcium uptake by the fragmented sarcoplasmic reticulum. Eur J Biochem 1976;69:79-86.

34 Somlyo AV, Somlyo AP: Strontium accumulation by sarcoplasmic reticulum and mitochondria in vascular smooth muscle. Science 1971;174:955-958.

-35 Pi M, Quarles LD: A novel cation-sensing mechanism in osteoblasts is a molecular target for strontium. J Bone Miner Res 2004;19: 862-869.

36 Brown EM: Is the calcium receptor a molecular target for the actions of strontium on bone? Osteoporos Int 2003;14(suppl 3):S25S34.

37 Quarles LD: Extracellular calcium-sensing receptors in the parathyroid gland, kidney, and other tissues. Curr Opin Nephrol Hypertens 2003;12:349-355.

38 Chang W, Tu C, Chen TH, Komuves L, Oda Y, Pratt SA, Miller S, Shoback D: Expression and signal transduction of calcium-sensing receptors in cartilage and bone. Endocrinology 1999;140:5883-5893.

-39 Nakagawa K, Pérez EC, Oh J, Santos F, Geldyyev A, Gross ML, Schaefer F, Schmitt $\mathrm{CP}$ : Cinacalcet does not affect longitudinal growth but increases body weight gain in experimental uraemia. Nephrol Dial Transplant 2008;23:2761-2767.

-40 Kirsch T, Wang W, Pfander D: Functional differences between growth plate apoptotic bodies and matrix vesicles. J Bone Miner Res 2003; 18:1872-1881. 